УДК 338.462

\author{
В.И. Суржиков ${ }^{1}$ \\ В. Д. Кравченко 2 \\ Владивостокский государственный университет экономики и сервиса \\ Владивосток. Россия
}

\title{
Оценка качества услуг международной гостиничной сети AZIMUT (на примере бизнес-отелей)
}

\begin{abstract}
В статье представлены авторская методика и результаты оценки качества услуг международной гостиничной сети AZIMUT. Для исследования были выбраны три отеля: AZIMUT Отель Смоленская, AZIMUT Отель Тульская и AZIMUT Отель Владивосток. Оценка проводилась по сорока критериям, объединённым в восемь блоков: транспортная доступность / местоположение; номерной фонд; услуги питания; спектр дополнительных услуг; конференц-залы; парковка; бизнес-центр; экскурсионные услуги. Полученные значения показателей по всем восьми блокам ранжировались. Для оценки была применена пятибалльная шкала, а также поправочные коэффициенты, в зависимости от важности блока. По результатам оценки наибольшее количество баллов набрал AZIMUT Отель Смоленская, на втором месте AZIMUT Отель Тульская и на третьем месте AZIMUT Отель Владивосток. Анализ отзывов бизнес-туристов, полученных из системы интернет-бронирования отелей «Booking», подтвердил результаты авторской оценки. Таким образом, авторами было выявлено, что бизнес-отели даже внутри одной гостиничной сети предоставляют услуги разного качества. Клиенты, получив услугу высокого качества в одном отеле, могут разочароваться в своих ожиданиях, посетив другой отель этой же сети. Предложенная авторами методика оценки качества услуг гостиничной сети может быть использована руководством для контроля и принятия управленческих решений.
\end{abstract}

Ключевые слова и словосочетания: гостиничная сеть, бизнес-отели, оценка, критерии оценки, качество услуг.

1 Суржиков Виктор Иванович - старший преподаватель Международного института туризма и гостеприимства; e-mail: Viktor.Surzhikov@ vvsu.ru

2 Кравченко Валерия Дмитриевна - бакалавр 1 курса Международного института туризма и гостеприимства; e-mail: lera.kravts.99@mail 
V. I. Surzhikov

V. D. Kravchenko

Vladivostok State University of Economics and Service

Vladivostok. Russia

\section{Assessment of the quality of services of the international hotel chain AZIMUT (for example, business hotels)}

The article presents the author's methodology and the results of assessing the quality of services of the international hotel chain AZIMUT. Three hotels were selected for the study: AZIMUT Hotel Smolenskaya, AZIMUT Hotel Tulskaya and AZIMUT Hotel Vladivostok. The assessment was carried out according to forty criteria combined into eight blocks: transport accessibility / location; room fund; catering services; range of additional services; conference rooms; parking; business center; excursion services. The obtained values of indicators for all eight assessment blocks were ranked. For the assessment, a five-point scale was applied, as well as correction factors, depending on the importance of the block. According to the results of the assessment, the greatest number of points was scored by AZIMUT Hotel Smolenskaya, the second place was taken by the AZIMUT Hotel Tulskaya and the third place by the AZIMUT Hotel Vladivostok. An analysis of the reviews of business tourists received from the "Booking" hotel booking system confirmed the results of the author's assessment. Thus, the authors found that business hotels, even within the same hotel chain, provide services of different quality. Having received a high quality service in one hotel, customers can be disappointed in their expectations by visiting another hotel of the same chain. The methodology proposed by the authors for assessing the quality of hotel chain services can be used by the management to control and make management decisions.

Keywords: hotel chain, business hotels, assessment, assessment criteria, quality of services.

\section{Введение}

В отечественной и зарубежной литературе исследованию международных гостиничных сетей уделяется недостаточно внимания. В связи с этим само понятие «гостиничная сеть» не является окончательно устоявшимся. В словаре-справочнике «Туризм, гостеприимство, сервис» приведено следующее определение: «...группа гостиничных предприятий, осуществляющих коллективный бизнес и находящихся под контролем руководства цепью, характеризующейся своей узнаваемой маркой, строгим соблюдением фирменных ценностей и наименованием услуг, качеством обслуживания и размещения, своим архитектурным дизайном, независимо от расположения гостиницы» [1].

В.С. Катькало и В.Н. Мукба под гостиничной сетью понимают «долгосрочное взаимовыгодное объединение гостиничных предприятий, а также фирм сопутствующих отраслей в единую структуру и систему стратегического сотрудничества с целью создания совместных отличительных компетенций» [2]. 
Е.Л. Путилина трактует понятие гостиничная сеть как «сложную многоуровневую систему, состоящую из различных предприятий гостиничной отрасли и характеризующуюся их стратегическим сотрудничеством как основным свойством данной системы» [3].

Аль-Робаи Ааливи определяет гостиничную сеть как «взаимосвязанную систему аналогичных гостиничных объектов, централизованно управляемых под одним брендом и использующих единые стратегические действия (стандарты качества, обслуживания, снабжения, концепция продвижения продукта) на основе общей системы информационного взаимодействия (системы бронирования и глобальные дистрибутивные системы)» [4].

Во всех формулировках исследуемого явления отмечаются следующие отличительные черты:

- объединение нескольких предприятий гостиничного бизнеса;

- принадлежность одному владельцу;

- общее управление;

- один фирменный знак;

- функционирование по единым стандартам высококачественного обслуживания.

Принадлежность к гостиничной сети предполагает формирование качественных услуг, которые должны поддерживаться на одинаково высоком уровне для всех предприятий, входящих в нее. Все основные гостиничные объединения должны иметь единые нормативы и параметры оснащения помещений, технологию и стандарты обслуживания. Однако общепринятой методики оценки качества услуг гостиничной сети нет.

Актуальность рассматриваемой проблемы, ее практическая значимость определили выбор темы научно-исследовательской работы и послужили основой для формулирования ее цели и задач.

Цель научно-исследовательской работы - разработать методику и провести оценку качества услуг международной гостиничной сети AZIMUT. Достижение поставленной цели потребовало решения ряда задач:

- исследовать существующие подходы к оценке гостиничных услуг;

- провести отбор собственных критериев для оценки;

- осуществить сбор данных по выбранным критериям;

- провести оценку качества услуг.

Предмет исследования. Предметом исследования является качество предоставляемых услуг бизнес-отелей международной гостиничной сети AZIMUT.

Методы исследования: статистический, метод равных интервалов, балльной оценки, сравнительного анализа.

\section{Основная часть}

В мире насчитывают более 300 гостиничных сетей. В 2019 году, по версии авторитетного американского журнала «Hotels», в десятку самых крупных по количеству отелей вошли: Оуо Rooms (45 600), Jin Jiang International Holdings Co. Ltd. (10 020), Wyndham Hotels \& Resorts (9280), Marriott International (7163), 
Choice Hotels International (7153), Hilton Worldwide Holdings (6110), HG (InterContinental Hotels Group) (5903), Huazhu Group Ltd. (5618), Accor (5036), BTG Hotels Group Co. (4450) [5].

Кроме международных гостиничных операторов в Российской Федерации функционируют национальные гостиничные сети. В 2019 году их количество составило 35 . На пять из них приходится $27 \%$ от общего количества гостиниц: Azimut Hotels (9\%), «ГОСТ Отель Менеджмент» (9\%), Amaks Hotels\&Resorts (6\%), «Маринс Парк Отель» (2\%), «Бархатные Сезоны» (1\%) [6].

Отели внутри одной, будь то мировой или национальной, сети должны иметь одинаковые нормативы и стандарты оснащения помещений, а также технологию и стандарты обслуживания. Клиенты, воспользовавшиеся однажды услугой сетевого отеля и удовлетворенные обслуживанием, с большой вероятностью снова остановятся в нём. И, конечно, будут ожидать такого же высокого уровня сервиса. Однако ввиду сложности структуры сетевой компании часто возникают трудности с эффективным контролем качества предоставляемых услуг.

Изучению проблемы, связанной с оценкой качества гостиничных услуг, посвящено немало работ. Чаще всего для оценки используют социологический метод, интервью, анализ жалоб и предложений [7; 8]. В основе большинства методик лежит во многом субъективный метод экспертной оценки [9]. В.Г. Топольник и А.В. Полякова предлагают оценку качества гостиничных услуг на основе порядка классификации объектов туристской индустрии, включающих гостиницы и иные средства размещения, горнолыжные трассы и пляжи, осуществляемой аккредитованными организациями, ныне утратившими силу [10]. М.В. Ефремова и О.В. Чкалова разработали методику оценки качества услуг в рамках процессного подхода, в основе которой лежит только процесс обслуживания [11]. Е.В. Печерица предложил алгоритм квазиточной оценки параметров качества услуг, который затруднительно применить на практике в силу использования сложного математического аппарата [12]. Интересной представляется методика оценки качества сервиса гостиниц на основе семантического анализа текста [13]. Однако и она не лишена субъективизма в силу возможности написания «заинтересованными лицами» отрицательных отзывов. Н.П. Липовка и Е.Ю. Саяпина разработали методику балльно-рейтинговой оценки качества гостиничных услуг, включающую в себя только десять показателей [14]. Все изученные методики не ориентированы на исследование услуг гостиничных сетей.

В связи с вышеизложенным авторами предпринята попытка разработать методику оценки качества гостиничных услуг на примере крупнейшей гостиничной сети AZIMUT. На данный момент сеть насчитывает 40 отелей уровня три, четыре и пять звёзд в четырёх странах мира. В 2004 году появились первые отели в Самаре, Уфе и Костроме. В 2008 г. сеть стала международной, открылись отели в Германии и Австрии. Большинство отелей сети являются бизнесотелями.

Для оценки были выбраны три бизнес-отеля в двух городах России: отели Смоленская, Тульская в городе Москва и отель Владивосток в городе Владиво- 
стоке. Все средства размещения прошли классификацию и принадлежат к категории гостиниц «четыре звезды».

AZIMUT Отель Смоленская представляет собой новую 23-этажную гостиницу бизнес-класса в центре Москвы. Располагается в историческом здании гостиницы «Белград» на Смоленской площади, недалеко от Арбата и Красной площади. Номерной фонд отеля составляет 474 номера. AZIMUT Отель Тульская стильный отель, расположенный в историческом здании 1867 года постройки лофт-квартала «Даниловская мануфактура». Номерной фонд отеля - 144 номера. AZIMUT Отель Владивосток - современный и единственный бизнес-отель на Дальнем Востоке с крупнейшим номерным фондом в 378 номеров.

Оценка проводилась по восьми блокам: транспортная доступность/местоположение; номерной фонд; услуги питания; спектр дополнительных услуг; конференц-залы; парковка; бизнес-центр; экскурсионные услуги.

Местоположение зачастую играет ключевую роль в выборе отеля. Отели с хорошей инфраструктурой, но плохой транспортной доступностью пользуются меньшим спросом. Блок транспортной доступности отелей представлен в табл. 1.

Таблица 1

Транспортная доступность отелей

\begin{tabular}{|l|c|c|c|}
\hline \multicolumn{1}{|c|}{ Название отеля/ критерий } & $\begin{array}{c}\text { AZIMUT Отель } \\
\text { Смоленская }\end{array}$ & $\begin{array}{c}\text { AZIMUT Отель } \\
\text { Тульская }\end{array}$ & $\begin{array}{c}\text { AZIMUT Отель } \\
\text { Владивосток }\end{array}$ \\
\hline $\begin{array}{l}\text { Расстояние до ближайшего } \\
\text { аэропорта, км }\end{array}$ & 31 & 40 & 51 \\
\hline $\begin{array}{l}\text { Расстояние до ближайшей ос- } \\
\text { тановки общественного транс- } \\
\text { порта, м }\end{array}$ & 80 & 100 & 800 \\
\hline $\begin{array}{l}\text { Расстояние до ближайшего } \\
\text { железнодорожного вокзала, км }\end{array}$ & 1 & 4 & 0,8 \\
\hline
\end{tabular}

Примечание: составлено авторами по [15].

Самой высокой транспортной доступностью характеризуется AZIMUT Отель Смоленская. Он имеет самые высокие показатели из всех исследуемых отелей: меньшее расстояние до ближайшего аэропорта и железнодорожного вокзала, ближайшей остановки общественного транспорта.

Далее проводилась оценка второго блока - номерной фонд. Все номера исследуемых отелей выполнены в концепции SMART, которая воплощает многолетний опыт гостеприимства и учитывает потребности гостей. Каждая деталь номера работает на создание уютной атмосферы и комфортного проживания, пространство максимально оптимизировано, дизайн лаконичен и прост. Разнообразие типов категорий номеров в каждом из отелей представлено в табл. 2. 
В.И. Суржиков, В.Д. Кравченко. Оценка качества услуг международной гостиничной сети

Таблица 2

Типы категорий номеров

\begin{tabular}{|l|l|l|}
\hline \multicolumn{1}{|c|}{ AZIMUT Отель Смоленская } & \multicolumn{1}{|c|}{ AZIMUT Отель Тульская } & \multicolumn{1}{c|}{$\begin{array}{c}\text { AZIMUT } \\
\text { Отель Владивосток }\end{array}$} \\
\hline SMART Одноместный & Отсутствует & Отсутствует \\
\hline SMART Двухместный & Отсутствует & Отсутствует \\
\hline SMART Стандарт & SMART Стандарт & SMART Стандарт \\
\hline SMART Супериор & SMART Супериор & SMART Супериор \\
\hline SMART Полулюкс & SMART Полулюкс & Отсутствует \\
\hline Отсутствует & SMART Полулюкс улучшенный & Отсутствует \\
\hline Отсутствует & Отсутствует & SMART Люкс \\
\hline SMART Стандарт (КЭ) & Отсутствует & SMART Стандарт (КЭ) \\
\hline SMАRT Полулюкс (КЭ) & Отсутствует & Отсутствует \\
\hline Отсутствует & Отсутствует & SMART Супериор (КЭ) \\
\hline Отсутствует & Отсутствует & SMART Люкс (КЭ) \\
\hline $\begin{array}{l}\text { Апартаменты с панорамным } \\
\text { видом с доступом в (КЭ) }\end{array}$ & Отсутствует & Отсутствует \\
\hline
\end{tabular}

Примечание: КЭ - клубный этаж, составлено авторами по [16-18].

Все отели имеют одинаковую звездность и принадлежат одной сети, однако количество типов категорий номеров отличается. AZIMUT Отель Смоленская предлагает своим гостям 7 категорий номеров, AZIMUT Отель Владивосток - 6, AZIMUT Отель Тульская - 4. Категории, которые совпадают у всех 3 отелей, это SMART Стандарт и SMART Супериор. Проведём подробную оценку и сравним их, исходя из размера и удобств в номерах (табл. 3).

Таблий 3

\section{Номерной фонд}

\begin{tabular}{|l|l|l|l|l|}
\hline \multicolumn{1}{|c|}{ Оборудование } & \multicolumn{1}{|c|}{$\begin{array}{c}\text { AZIMUT Отель } \\
\text { Смоленская }\end{array}$} & \multicolumn{1}{c|}{$\begin{array}{c}\text { AZIMUT Отель } \\
\text { Тульская }\end{array}$} & \multicolumn{1}{|c|}{$\begin{array}{c}\text { AZIMUT Отель } \\
\text { Владивосток }\end{array}$} \\
\hline \multicolumn{2}{|c|}{ SMART Стандарт } \\
\hline Площадь, м
\end{tabular}


Окончание табл. 3

\begin{tabular}{|c|c|c|c|}
\hline Оборудование & $\begin{array}{c}\text { AZIMUT Отель } \\
\text { Смоленская }\end{array}$ & $\begin{array}{c}\text { AZIMUT Отель } \\
\text { Тульская }\end{array}$ & $\begin{array}{l}\text { AZIMUT Oтель } \\
\text { Владивосток }\end{array}$ \\
\hline Сейф & + & + & + \\
\hline Фен & + & + & + \\
\hline Тапочки, полотенца & + & + & + \\
\hline Халат & + & $\begin{array}{l}\text { По требованию } \\
\text { гостя }\end{array}$ & $\begin{array}{l}\text { По требованию } \\
\text { гостя }\end{array}$ \\
\hline Чайная станция & + & + & - \\
\hline \multicolumn{4}{|c|}{ SMART Супериор } \\
\hline Площадь, м² & 22 & 20 & 18 \\
\hline Наличие рабочей зоны & + & + & + \\
\hline Мини-бар & + & + & + \\
\hline Телефон & + & + & + \\
\hline Интернет и телевидение & + & + & + \\
\hline Сейф & + & + & + \\
\hline Фен & + & + & + \\
\hline Тапочки, полотенца & + & + & + \\
\hline Халат & + & $\begin{array}{l}\text { По требованию } \\
\text { гостя }\end{array}$ & $\begin{array}{l}\text { По требованию } \\
\text { гостя }\end{array}$ \\
\hline Чайная станция & + & + & + \\
\hline
\end{tabular}

Примечание: составлено авторами по [16-18].

Наполнение номеров во всех трех отелях идентично, за исключением незначительных деталей. Существенно различаются площади номеров. Так, самые большие номера обеих категорий находятся в AZIMUT Отель Смоленская, наименьший номер категории SMART Стандарт - в AZIMUT Отель Тульская, а наименьший номер категории SMART Супериор - в AZIMUT Отель Владивосток. Несмотря на разницу в площадях, номера во всех трех отелях соответствуют классификации согласно Постановлению Правительства РФ от 18.11.2020 № 1860 «Об утверждении Положения о классификации гостиниц» [19].

Предоставление питания также является основной услугой отеля. От предприятий питания гости всегда ожидают высокого качества обслуживания и разнообразия блюд. Для их оценки применимы следующие критерии: количество предприятий питания в здании отеля, соотношение посадочных мест к количеству номеров в отеле, наличие банкетного зала, его вместимость и площадь (табл. 4). 
Анализ услуг питания

\begin{tabular}{|l|c|c|c|}
\hline \multicolumn{1}{|c|}{ Название отеля/ критерий } & $\begin{array}{c}\text { AZIMUT Отель } \\
\text { Смоленская }\end{array}$ & $\begin{array}{c}\text { AZIMUT Отель } \\
\text { Тульская }\end{array}$ & $\begin{array}{c}\text { AZIMUT Отель } \\
\text { Владивосток }\end{array}$ \\
\hline $\begin{array}{l}\text { Количество предприятий пита- } \\
\text { ния в здании отеля }\end{array}$ & 4 & 1 & 1 \\
\hline Вместимость банкетного зала & 0 & 0 & 300 \\
\hline Площадь банкетного зала & 0 & 0 & $330 \mathrm{~m}^{2}$ \\
\hline $\begin{array}{l}\text { Соотношение количества номе- } \\
\text { ров к количеству посадочных } \\
\text { мест в ресторанах }\end{array}$ & 0,77 & 2,88 & 4,2 \\
\hline
\end{tabular}

Примечание: составлено авторами по [16-18].

Количество предприятий питания значительно разнится. Банкетный зал присутствует только в AZIMUT Отель Владивосток. Значение количества человек, приходящихся на одно место в ресторане, варьирует от 0,77 до 4,2. Этот показатель свидетельствует о том, что отсутствует соотношение количества номеров отеля и полезной площади предприятия общественного питания.

Спектр дополнительных услуг довольно обширен. В каждом из отелей есть бар, тренажерный зал, прачечная / химчистка, круглосуточное обслуживание номеров. Однако перечень дополнительных услуг не является единым для всех отелей. В некоторых из них отсутствует услуга проката автомобилей / каршеринг, sра-салон, магазин сувениров, возможность размещения с животными и библиотека (табл. 5).

Таблица 5

Спектр дополнительных услуг

\begin{tabular}{|l|c|c|c|}
\hline \multicolumn{1}{|c|}{ Услуга } & $\begin{array}{c}\text { AZIMUT Отель } \\
\text { Смоленская }\end{array}$ & $\begin{array}{c}\text { AZIMUT Отель } \\
\text { Тульская }\end{array}$ & $\begin{array}{c}\text { AZIMUT Отель } \\
\text { Владивосток }\end{array}$ \\
\hline Прокат автомобилей / каршеринг & + & - & + \\
\hline Бар & + & + & + \\
\hline Тренажерный зал & + & + & + \\
\hline Sра-салон & + & - & + \\
\hline Магазин сувениров & + & + & + \\
\hline Прачечная/химчистка & + & + & + \\
\hline $\begin{array}{l}\text { Круглосуточное обслуживание } \\
\text { номеров }\end{array}$ & + & + & + \\
\hline Размещение с животными & - & + & + \\
\hline Библиотека & - & + \\
\hline
\end{tabular}

Примечание: составлено авторами по [16-18]. 
Чаще всего бизнес-туристы приезжают в отели, чтобы провести встречу со своими партнерами. Поэтому одной из важнейших услуг является аренда конференц-залов. Для оценки конференц-залов в отелях нами выбраны следующие критерии: их количество, количество посадочных мест в них, возможность трансформации и наличие необходимой аппаратуры (табл. 6).

Таблица 6

Анализ конференц-залов, парковок, бизнес-центров

\begin{tabular}{|c|c|c|c|}
\hline Название отеля / критерий & $\begin{array}{l}\text { AZIMUT Отель } \\
\text { Смоленская }\end{array}$ & $\begin{array}{l}\text { AZIMUT Отель } \\
\text { Тульская }\end{array}$ & $\begin{array}{l}\text { AZIMUT Отель } \\
\text { Владивосток }\end{array}$ \\
\hline \multicolumn{4}{|c|}{ Конференц-залы } \\
\hline Количество конференц-залов, ед. & 10 & 1 & 3 \\
\hline Возможность трансформации & + & - & + \\
\hline Общая вместимость всех залов, м² & 955 & 90 & 490 \\
\hline Наличие аппаратуры & + & + & + \\
\hline \multicolumn{4}{|c|}{ Парковки } \\
\hline Охраняемая или нет & + & + & - \\
\hline Бесплатная или нет & - & + & - \\
\hline Количество машино-мест, ед. & 21 & 5 & 30 \\
\hline $\begin{array}{l}\text { Соотношение количества номеров } \\
\text { к количеству мест }\end{array}$ & 22,6 & 28,8 & 12,6 \\
\hline \multicolumn{4}{|c|}{ Бизнес-центр } \\
\hline $\begin{array}{l}\text { Количество рабочих мест в биз- } \\
\text { нес-центре, ед. }\end{array}$ & 4 & 1 & 2 \\
\hline Компьютер & + & + & + \\
\hline Принтер & + & + & + \\
\hline Цветной принтер & + & - & - \\
\hline Сканер & + & + & + \\
\hline
\end{tabular}

Примечание: составлено авторами по [16-18].

Практически все значения критериев значительно варьируют. Не везде есть возможность трансформации залов по требованию клиента. Для бизнес-туриста немаловажным в отеле является наличие парковки и бизнес-центра. Бесплатную и охраняемую парковку предоставляет только AZIMUT Отель Тульская. При этом её вместимость составляет всего 5 машино-мест. Наполнение бизнесцентров везде идентично, за исключением отсутствия цветной печати в AZIMUT Отель Тульская и AZIMUT Отель Владивосток. 
После конференций, встреч с партнерами и переговоров деловые туристы желают отдохнуть и провести время с пользой. В этом им может помочь отель, организовав интересную экскурсию по городу. AZIMUT Отель Смоленская и AZIMUT Отель Тульская предоставляют практически идентичный спектр экскурсионных услуг со скидкой для своих гостей: уникальные прогулки с местными жителями в сервисе Localie (10\%), посещение смотровых площадок PANORAMA360 в Москва-сити (15\%), HIGH PORT 354 (20\%), Останкинской телебашни (0\%), экскурсии по Москве на автобусах City Sightseeing Moscow (10\%), посещение Третьяковской галереи (100\%), предоставление аудиогида izi.TRAVEL (100\%). AZIMUT Отель Владивосток экскурсионные услуги не предоставляет.

Полученные значения показателей по всем восьми блокам оценки ранжировались на основе метода равных интервалов. Значению, попавшему в определенный интервал, присваивался балл. Для оценки применялась 5-балльная шкала, а также поправочные коэффициенты в зависимости от важности блока. Результаты оценки представлены в табл. 7.

Таблица 7

\section{Результаты оценки}

\begin{tabular}{|l|c|c|c|c|}
\hline \multicolumn{1}{|c|}{ Критерий } & $\begin{array}{c}\text { Поправочный } \\
\text { коэффициент }\end{array}$ & $\begin{array}{c}\text { AZIMUT } \\
\text { Отель } \\
\text { Смоленская }\end{array}$ & $\begin{array}{c}\text { AZIMUT } \\
\text { Отель } \\
\text { Тульская }\end{array}$ & $\begin{array}{c}\text { АZIMUT } \\
\text { Отель } \\
\text { Владивосток }\end{array}$ \\
\hline Местоположение & 0,14 & 2,1 & 1,26 & 0,98 \\
\hline Номерной фонд & 0,14 & 14,28 & 13,86 & 12,32 \\
\hline Рестораны & 0,10 & 1,2 & 0,5 & 1,2 \\
\hline Спектр дополнительных услуг & 0,09 & 5,13 & 4,77 & 5,49 \\
\hline Конференц-залы & 0,16 & 4,48 & 2,24 & 3,04 \\
\hline Парковка & 0,12 & 1,68 & 1,92 & 0,96 \\
\hline Бизнес-центр & 0,16 & 4 & 2,72 & 2,88 \\
\hline Экскурсионные услуги & 0,09 & 3,6 & 3,15 & 0 \\
\hline Сумма & 1 & 36,47 & 30,42 & 26,87 \\
\hline
\end{tabular}

По результатам оценки наибольшее количество баллов набрал AZIMUT Отель Смоленская (Москва), на втором месте AZIMUT Отель Тульская (Москва) и на третьем месте AZIMUT Отель Владивосток.

Для проверки достоверности полученных результатов нами были изучены отзывы бизнес-туристов и проведён сравнительный анализ по следующим критериям: расположение отеля; комфорт и удобства; качество сервиса; чистота; соотношение цены/качества (рисунок). 


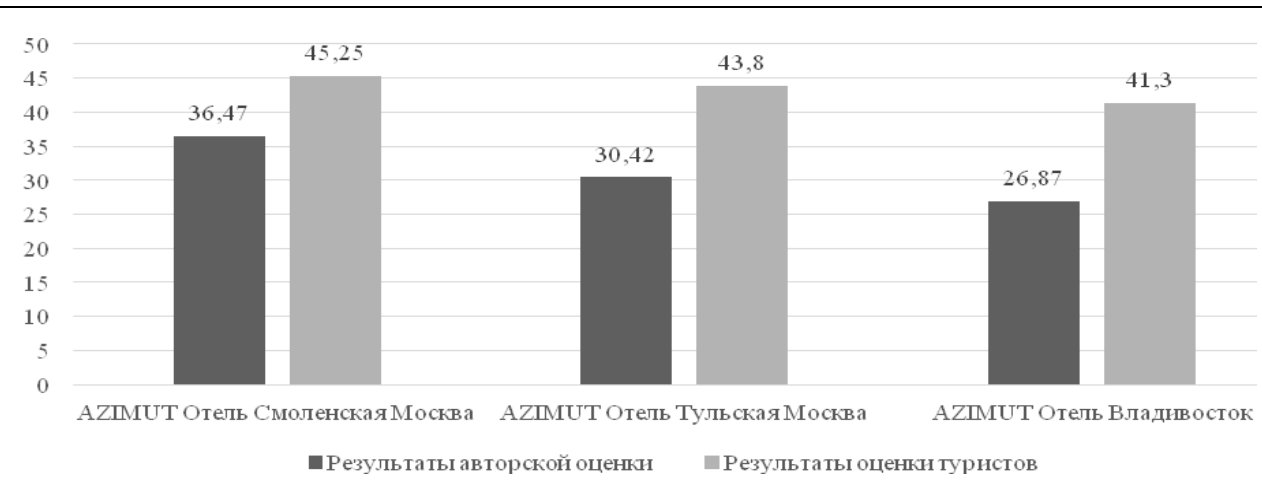

Рисунок. Соотношение результатов авторской оценки и оценки бизнес-туристов, баллы

Отзывы бизнес-туристов подтверждают результаты авторской оценки. AZIMUT Отель Смоленская (Москва) занимает первое место среди оцениваемых отелей (45,3 балла), на втором месте - AZIMUT Отель Тульская (Москва) (43,8 балла) и на третьем - AZIMUT Отель Владивосток (41,3 балла) [20].

\section{Выводы и научная новизна}

В ходе исследования поставлены и выполнены следующие задачи:

- исследована дефиниция «гостиничная сеть», определены её отличительные признаки;

- исследованы существующие подходы к оценке качества гостиничных услуг. Определено, что все они имеют свои недостатки и не ориентированы на исследование качества услуг гостиничных сетей;

- для оценки проведён отбор сорока собственных критериев;

- осуществлён сбор данных по выбранным критериям для бизнес-отелей Смоленская, Тульская, Владивосток гостиничной сети AZIMUT;

- проведена оценка качества услуг. На основе полученных результатов нами было выявлено, что бизнес-отели даже внутри одной гостиничной сети значительно отличаются между собой, предоставляя услуги разного качества. Поэтому клиенты, получив услугу высокого качества в одном отеле, могут разочароваться в своих ожиданиях, посетив другой отель этой же сети.

Научная новизна исследования заключается в предложенной авторами методике оценки качества услуг гостиничной сети, которая может быть использована руководством для контроля и принятия решений, нивелирующих сложившуюся ситуацию.

1. Туризм, гостеприимство, сервис: словарь-справочник / Г.А. Аванесова, Л.П. Воронкова, В.И. Маслов, А.И. Фролов. - Москва: Аспект Пресс, 2002. - 367 с.

2. Катькало В.С., Мукба В.Н. Международные гостиничные сети: специфика организации и типология стратегий развития // Вестник Санкт-Петербургского университета. - 2004. - Cер. 8, Вып. 4 (32). - С. 3.

3. Путилина Е.Л. Формирование и развитие национальных гостиничных сетей в России: автореф. дис. ... канд. экон. наук: 08.00.05. - Москва, 2011. - 27 с. 
4. Карар А.С. Развитие международных гостиничных сетей // Журнал международного права и международных отношений. - 2012. - Вып. 2. - С. 89.

5. Hotels 325 Rank // Hotels Magazine. - URL: https://www.hotelsmag.com/ (дата обращения: 20.04.2021).

6. Кто лидирует на рынке гостиничных операторов России? - Текст: электронный // PwC: [сайт]. - URL: https://www.pwc.ru/ru/materials/pwc-kto-lidiruyet-na-rynkegostinichnykh-operatorov.pdf (дата обращения: 25.04.2021).

7. Галенко Е.В., Овчаренко Н.П. Оценка степени удовлетворенности гостя качеством гостиничных услуг // Азимут научных исследований: экономика и управление. 2017. - Т. 6, Вып. 4 (21). - С. 79.

8. Лебедева Т.Е., Лазутина А.Л., Башкаева О.А. Оценка качества услуг гостиниц Marriott в Санкт-Петербурге // Наука и бизнес: пути развития. - 2019. - Вып. 6(96). C. 164.

9. Погорелова Э.И., Сергеев А.А. Качество обслуживания туристов в гостиницах как фактор привлечения туристов // Интерактивная наука. - 2017. - Вып. 11. - С. 193.

10. Топольник В.Г., Полякова А.В. Количественная оценка качества гостиничных услуг // Стандарты и качество. - 2017. - Вып. 6 (963). - С. 94.

11. Ефремова М.В., Чкалова О.В. Анализ качества гостиничных услуг на основе процессного подхода // Экономический анализ: теория и практика. - 2014. Вып. 26(377). - С. 10.

12. Печерица Е.В. Алгоритм квазиточной оценки параметров качества услуг для гостиниц различных категорий // Журнал правовых и экономических исследований. 2010. - Вып. 2. - С. 78.

13. Матвеев А.А. Оценка качества сервиса гостиниц с применением методики семантического анализа текста // Вестник Национальной академии туризма (НАТ). - 2018. Вып. 4(48). - С. 37.

14. Липовка Н.П., Саяпина Е.Ю. Качество гостиничных услуг - элемент маркетинговой стратегии предприятия // Ученые записки Комсомольского-на-Амуре государственного технического университета. - 2020. - Вып. 1(41). - С. 99.

15. Яндекс карты: [сайт]. - URL: https://yandex.ru/maps/ (дата обращения: 10.03.2021).

16. AZIMUT Hotels Смоленская: [сайт]. - URL: https://azimuthotels.com/ru/moscow/azimuthotel-smolenskaya (дата обращения: 15.03.2021).

17. AZIMUT Hotels Тульская: [сайт]. - URL: https://azimuthotels.com/ru/moscow/azimuthotel-tulskaya (дата обращения: 15.03.2021).

18. AZIMUT Hotels Владивосток: [сайт].- URL: https://azimuthotels.com/ru/vladivostok/azimut-hotel-vladivostok (дата обращения: 15.03.2021).

19. Об утверждении Положения о классификации гостиниц: Постановление Правительства РФ от 18.11.2020 № 1860. - Текст: электронный // СПС «Консультант Плюс»: [сайт]. - URL: http://www.consultant.ru/document/cons_doc_LAW_368948/ (дата обращения: 15.03.2021).

20. Система интернет-бронирования отелей «Booking»: [сайт]. - URL: https://www.booking.com (дата обращения: 18.04.2021).

\section{Транслитерация}

1. Turizm, gostepriimstvo, servis: slovar'-spravochnik / G.A. Avanesova, L.P. Voronkova, V.I. Maslov, A.I. Frolov. - Moskva: Aspekt Press, 2002. - 367 s. 
2. Kat'kalo V.S., Mukba V.N. Mezhdunarodnye gostinichnye seti: specifika organizacii i tipologiya strategij razvitiya // Vestnik Sankt-Peterburgskogo universiteta. - 2004. - Ser. 8, Vyp. 4 (32). - S. 3.

3. Putilina E.L. Formirovanie i razvitie nacional'nyh gostinichnyh setej v Rossii: avtoref. dis. ... kand. ekon. nauk: 08.00.05. - Moskva, 2011. - 27 s.

4. Karar A.S. Razvitie mezhdunarodnyh gostinichnyh setej // ZHurnal mezhdunarodnogo prava i mezhdunarodnyh otnoshenij. - 2012. - Vyp. 2. - S. 89.

5. Hotels 325 Rank // Hotels Magazine. - URL: https://www.hotelsmag.com/ (data obrashcheniya: 20.04.2021).

6. Kto lidiruet na rynke gostinichnyh operatorov Rossii? - Tekst: elektronnyj // PwC: [sajt]. URL: $\quad$ https://www.pwc.ru/ru/materials/pwc-kto-lidiruyet-na-rynke-gostinichnykhoperatorov.pdf (data obrashcheniya: 25.04.2021).

7. Galenko E.V., Ovcharenko N.P. Ocenka stepeni udovletvorennosti gostya kachestvom gostinichnyh uslug // Azimut nauchnyh issledovanij: ekonomika i upravlenie. - 2017. T. 6, Vyp. 4 (21). - S. 79.

8. Lebedeva T.E., Lazutina A.L., Bashkaeva O.A. Ocenka kachestva uslug gostinic Marriott v Sankt-Peterburge // Nauka i biznes: puti razvitiya. - 2019. - Vyp. 6(96). - S. 164.

9. Pogorelova E.I., Sergeev A.A. Kachestvo obsluzhivaniya turistov v gostinicah kak faktor privlecheniya turistov // Interaktivnaya nauka. - 2017. - Vyp. 11. - S. 193.

10. Topol'nik V.G., Polyakova A.V. Kolichestvennaya ocenka kachestva gostinichnyh uslug // Standarty i kachestvo. - 2017. - Vyp. 6 (963). - S. 94.

11. Efremova M.V., Chkalova O.V. Analiz kachestva gostinichnyh uslug na osnove processnogo podhoda // Ekonomicheskij analiz: teoriya i praktika. - 2014. - Vyp. 26(377). S. 10.

12. Pecherica E.V. Algoritm kvazitochnoj ocenki parametrov kachestva uslug dlya gosti-nic razlichnyh kategorij // ZHurnal pravovyh i ekonomicheskih issledovanij. - 2010. Vyp. 2. - S. 78.

13. Matveev A.A. Ocenka kachestva servisa gostinic s primeneniem metodiki semanticheskogo analiza teksta // Vestnik Nacional'noj akademii turizma (NAT). - 2018. Vyp. 4(48). - S. 37.

14. Lipovka N.P., Sayapina E.YU. Kachestvo gostinichnyh uslug - element marketingovoj strategii predpriyatiya // Uchenye zapiski Komsomol'skogo-na-Amure gosudarstvennogo tekhnicheskogo universiteta. - 2020. - Vyp. 1(41). - S. 99.

15. Yandeks karty: [sajt]. - URL: https://yandex.ru/maps/ (data obrashcheniya: 10.03.2021).

(С В.И. Суржиков, 2021

(C) В.Д. Кравченко, 2021

Для цитирования: Суржиков В.И., Кравченко В. Д. Оценка качества услуг международной гостиничной сети AZIMUT (на примере бизнес-отелей) // Территория новых возможностей. Вестник Владивостокского государственного университета экономики и сервиса. - 2021. - Т. 13, № 2. - С. 48-60.

For citation: Surzhikov V.I., Kravchenko V.D. Assessment of the quality of services of the international hotel chain AZIMUT (for example, business hotels), The Territory of New Opportunities. The Herald of Vladivostok State University of Economics and Service, 2021, Vol. 13, № 2, pp. 48-60.

DOI https://doi.org/10.24866/VVSU/2073-3984/2021-2/048-060

Дата поступления: 14.05.2021.

60 